\title{
The Chinese and Foreign Sports and Sports History Research
}

\author{
Bing Zhang ${ }^{1, *}$, Kunling Qin ${ }^{2}$, Libin Yu ${ }^{1}$ \\ ${ }^{1}$ Institute of Physical Education, Huanggang Normal University, \\ Huangzhou 438000, Hubei, China \\ ${ }^{2}$ Yidu Gaobazhou Middle School, Yidu 443300, Hubei, China \\ tiyuxi@qq.com
}

\begin{abstract}
Generation of the subject is sports ideology in modern times, the development of sports theory to a certain level of product, it is more and more regarded by the theory of sports workers, this paper expounds the concept and nature of sports ideology; The relationship between the sports ideology and sports; The purpose and value of the thought history research; Research method deals with the methods of sports ideology, the formation of the subject for the sports ideology provides theory. Using the method of literature and logic, this paper summarizes the research development trend of international sports, analyzed the new trend of the contemporary sports. Research of the status quo of domestic sports research carried on the thorough discussion, think in recent 10 years, our country sports history research has a new change, new development and new breakthrough; In books, textbooks published and diversified research method; A young academic team; Increase international academic exchanges, etc. From the point of the present development of China's sports, sports study basic end/break 0, sports a new round of the boom is coming.
\end{abstract}

Keywords: sports ideology Sports development both at home and abroad

\section{INTRODUCTION}

The development of undertakings of physical culture and sports, the first is in the thought and updating of the concept and development. Therefore, sports history research is more important. Based on some theory about sports history research between some shallow discussed, aimed at, the author hopes that more scholars can come into the research field of sports history, the discipline to play its role in the development of sports industry in China (Tang et al., 2013). Therefore, timely understand and grasp the current domestic and foreign current situation of the development of sports and the relationship between sports and social development, the development of the sports today, looking for a new law, it is an important task of sports research (Liu, 2014).

\section{The CONCEPT AND NATURE OF SPORTs History}

Study sports ideology, should first know sports discipline connotation of intellectual history, and its research fields and properties. On this basis, to be able to further in-depth study, otherwise, we will inevitably be some deviation in the research process (Xing et al., 2013).

So-called sports ideology, we can analysis from the three concepts, namely "sport", "thinking" and "history". In terms of sports is a word, is not yet have a unified definition, no cloud, but no matter what kind of view, all think sports are the object of the research and the role is human body, movement is the basic means (Liang, 2013); "Thought" is people thinking about things. In that case, sports thought can also be seen as people thinking about the human body and exercise various phenomena as a result, the sports theory and a new spirit, The "history", the so-called "history" history is things change and evolution of knowledge are described. Thought has its change and evolution of the order; this is the history of ideas. According to the connotation of the concept of the three, you can define the narrative to sports ideology about human body and exercise the phenomenon of the theory and the spirit of change and evolution of the discipline.). We think it is basically reflects the "sport", and "thinking" and "history" (Jiang, 2014). 


\section{SPORTS RESEARCH TREND}

The origin of the main research contents include: sports sports; The role of sports in social development process and status; Sports in the social form of manifestation; Sports and productivity, the relationship between the economic development; Sports content at different stages and its relationship with people demand; Sports and culture in each period, the relationship between the social restriction, purpose and task; The period of the sports of the main means, methods and contents, etc $(\mathrm{Pu}, 2013)$.

Sports research and collection of the data; For the existing data, using dialectical materialism viewpoint is analyzed, a more scientific results; The results are reasonable, show the development of the sports activities and evolution; Pay attention to relation and influence between different sports activities, to correctly handle the relationship between the history and special history(Chen et al., 2013).

Sports research as the Renaissance and the rise of prosperity. First starts from the classical sports research. After the Second World War, international communication increasingly frequent, sports researchers' research scope has been expanded. At this stage, the research of sports from the classical sports research on a new scientific way, in the various historical stages of sports development and the research on the history of an individual, the western sports gradually and Oriental sports as an important part of the study of sports, further expanded the field of sports research(Li et al., 2013).

About in the late $1980 \mathrm{~s}$ and early $90 \mathrm{~s}$, although the UK there is no sports related courses in university courses, plus there are lots of difficulties in research direction but also established the status of sports discipline. At the time of China, Japan and South Korea in this aspect of the research is quite good, also many, and Japan, South Korea on the research methods and the like. Japanese scholars focus on sports, while South Korea into the study. Mr Cheng Shijun differences of Chinese and foreign sports literature and history research is comprehensively analyzed the sports research [5]. In recent decades, western sports roughly divided into two research trends: one is the research in the field of sports history in the deepening and extension; Another is the use of sports history research this sports service platform, focus on research and development of physical culture research, making it a geared to the needs of contemporary society, serve the masses of western sports discipline characteristic of research direction. Asian sports research mainly concentrated in a few countries such as China, Japan and South Korea, and the research direction is also similar, but the Chinese sports history in the ancient history of sports, martial arts, sports, sports ideology has obvious advantages in cultural history research, but the researchers are not interested in the entire Asian sports (Song, 2013).

Foreign sports research and development of the following reasons: one, 18, during the nineteenth century, western science is developing rapidly, the top academic research, especially in anthropology, ethnology, sociology, and vigorously promote the creation and development of sports history; Second, the academic team composition and growing, especially in Britain, Germany and other countries in the 20th century university teachers actively join in the research of sports team, presented the cooperation of amateur and professional scholars, and even a historian joined the sports study, the research on western sports and sports ideology in both depth and is an extension from the breadth; Three, eight of the last century, western countries are in the ninety s in sports discipline status at the same time, published and some important research results, have great effects on western sports development; Four, amid growing global from all walks of life to sports academic exchanges, promote the general improvement in the level of national sports researchers.

\section{RELATIONSHIPS OF SPORTS AND SPORTS IDEOLOGY}

Sports are a narrative of sports theory and practice of change the order of development of learning. Look from its research object and range, including two aspects, namely the sports theory (including sports theory, claim, concepts, and in these theories, the concept of claim and domination to formulate guidelines, policies and regulations, etc.) and sports practice (system, sports equipment, sports venues, sports, performance, games site technique, time, and relevant documents, etc.). Sports history and home together constitute complete sports. Sports ideology, therefore, is a part of sports, sports than sports narrow the scope of the thought history research. Thought to guide practice, practice and enriches the ideas, the two together constitute the history. So are whole and the part of the relationship between sports and sports ideology. If you don't study in sports research sports thought would lose its 
historical roots, will be an incomplete, no thorough research. On the other hand, the sports history research if not into sports this big background, it will be out of the inheritance of traditional culture, also can be non-existent, lost the significance of the research.

A complete sport is sports ideology and home this two parts, that what is the relationship and difference between the two parts, so it is necessary to make clear the relationship between the two. Thought is a theory or a kind of ideal and faith, but practice is the theory in the reflection of reality. That is a kind of practice activity there is always a certain ideological roots, people are always in a thought at the mercy of the engaged in certain activities. Sports belong to the idea of internal system, and the idea system is often reflected in a certain range of space and time, reflected by the external sports practice, therefore, we are studying sports at home, you must first research influence the ideological root of its emergence and development, the study of sports practice a necessary procedure. Before we write an article, for example, the first thing to conception, conception is equivalent to the content of the ideological and theoretical roots, however, we strictly according to this conception to describe, finally according to this conception to adorn article again, only through such steps to write a center, a thinking of the article. , of course, there are times when a idea may not immediately present in practice, that is sure to be a kind of practical activity, but this kind of thought for the future of the establishment of the sports practice or system may have a certain influence, may also is a very deep influence. Such as French famous thinker and educator of the enlightenment pioneers Rousseau, his naturalism sports thought at the time of the French was not recognized. Not to mention put them into practice, however, after decades of his naturalism sports thought first adopted in Germany, near the acclaimed throughout Europe, originally many famous educators, sports scientists all inheritance and development of his thought. Until the early 20th century American pragmatism view on sports thought and children's center, with it's the colour of naturalism.

Home sports history and, therefore, has a very close relationship, both in the study of sports, if you don't study sports thought, could not understand well the spirit of sports practice activities, if you don't study sports practice, also can't fastidious the true meaning of sport thoughts. They are in the study of sports supplement each other, be short of one cannot two aspects.

\section{For Nearly 10 Years, the New Development of Sports History, the New BREAKTHROUGH}

Entering the 21st century, great changes have taken place in the whole Chinese society, open to the outside of the portal more open, western ideas and culture as the tide xie pours in and the traditional culture of China is very big impact, in such a situation, "crisis" occurred in the history in China, sports history also has changed a lot. Though some scholars in the study of sports had a lot of trouble and difficulties in the process, but their unremitting efforts, in the face of difficulties, never shy, according to the target and reality gap breach, after several years of "cool", some scholars put this paragraph of time is called the "break"), and finally reached the prosperity of the sports career. In the years to 2000 to the present, for the study of sports, besides the traditional research methods, also can draw lessons from some research methods of other subjects, and then combining with other subjects scholars to join, so there is the interdisciplinary fusion research, so as to research in the field of research breaks through the traditional simplification way, open up a new field or a new growing point of the study of sports, such as anthropology, ethnology, folklore, the introduction of culturology, sociology, geography, science, and to join us for sports research provides a new direction, to add new vitality, make the sports research presents "schools of thought contend, the flowers for put" new situation.

Sun is in the northeast Asia sports study review ten years in the 10 years from 1994 to 2003 were analyzed in northeast Asia sports and history of the five kingdoms academic conference, he thought of the fourth from 2001 to 2003 the fifth is a development of the research of sports history. He said Chinese scholars to study modern sports walk in front of the other countries of Asia. China's bid to host the 4th conference seminars in 2001, established the theme of "sports and social progress", the theme of mark northeast Asia sports history in modernization and Chinese historiography research modernization the arrival of the new high tide, of course, it is also the cause of the modernization of China attaches great importance to the sports and the Olympic research is one of the characteristics of [6]. In addition, held in Italy in September 2003 to attend the 7th international conference on historical society, there are many scholars attended the 8th European international sports meetings held in Greece. Held in Beijing sports university in our country in 2005 the theme of "2005 China's 
first female and the international sports culture" of the BBS, attendance are world famous scholars, sports scholar, professor, meeting report in English in different occasions, won the foreign experts unanimously praised.

International exchange activities, not only the sports scholars gradually with international sports discipline, has a lot to promote for constantly explore new areas of study, absorb the research achievements of scholars around the world, to a certain extent, has brought New Zealand sports research

Method, new thinking, make sports historiographical trend more active and stronger vitality.

\section{RESEARCH METHODS OF SPORTS AND SPORTS IDEOLOGY}

\subsection{Sports Thoughts Inquiry Method.}

Sports ideology is artificial carrier and cannot exist alone, it is a kind of subjective understanding, people of sports is a kind of idea, and the ideas and proposals are made up of some representative thinkers. First in the sports history research, therefore, should from the thought research of characters. The specific research steps:

- The first step: induction. Search and collect related sports thought representative historical data and comments. These materials in addition to including the character's life and work, historical background, and more importantly, their books, articles, and related theory, because their sports ideology mainly placed in his books, articles, and theory.

- The second step: critical method. Will collect data processing and comparison analysis, to identify its authenticity, weight, the branch, select the representative historical data, to abandon fringes modified content.

- The third step: summarized and described. According to choose those with essential information, the content of the representative, the sorting, summary and generalization, to build the connotation of the idea, and then recorded, for later use.

- The fourth step: to judge its value.

\subsection{The General Form of Sports History Research}

- Research on sports ideology, not a fixed pattern, but from a complete research process should include the following aspects:

- Describe the social (including times and culture) and national character.

- Narration in the context of the history of how sports thought the thought and the historical background of the relationship.

- Describe the sports system.

- Describe sports character's life, work, and study the character of philosophy and education thought, etc.

- And generalizes the core of sports thoughts.

- On the character of sports thought value evaluation.

Above is we study some theoretical problems of sports ideology of bedrock, due to the limited level, hard to avoid is improper, invite the experts and scholars put forward valuable opinion, also hope that the research achievements of the sports thought and solve the problem of sports practice better combine study as an important subject in the future, to make continuous research and development of sports ideology.

\section{Prospects of Development of Sports History}

Since the 1980 s, sports research has encountered some setbacks, brief landslides occurred, academic circles called "two climax of intermittent period", also known as the "crisis" of history. But overall is a process of constant development, there has been brilliant, there have been declining. At present, our country is comprehensively deepen reform and the period of cultural powers into power, the historical development of sports is a great opportunity, in the present status of the sports research in China, puts forward some forecasts: 


\subsection{In the Research Area}

In the current rapid development under the pattern of the global economy and culture, should be sports history to explore new channels and new research direction, the simplification research for the study of the comprehensive development of transformation, which makes the future sports study more meaningful, to further improve the research methods.

\subsection{On the Research Methods}

To scientific, efficient and comprehensive research method into sports history studies. In recent years, a variety of disciplines overlapping fusion theory and research methods, and then introduce sports history research, has a very important reference value. Sports history research in the future, therefore, will give priority to with textual research, the research methods of pursuing, in other research method is complementary, strictly implement the "norm" in the process of research, "complementary empirical analysis", "traditional research", the principle of complementary "new historiography", strive to make research to develop and deepen, it will be a new feature of sports history research.

\subsection{Deals With the "New" and "Old" is the Focus of the Transformation of Sports}

As the change of The Times, the development of science and the progress of the society, people's minds change a lot, also deal with things in using the "new" way of thinking and method, but it's lateral reflects a problem: people are good at using the way to deal with the problem now, and your way to the traditional methods, that is to abandon the old new, so want to change idea, strive for both, the right attitude towards the new methods and ways, to do the "continuity". In addition, in terms of research contents, and many research outlines, like the ancient sports periodic history, culture, sports, social history, the folk custom history, many aspects have very big research space, waiting for us to study. We always think that have to be content with reality, to ignore those things, but now everything is on the basis of the evolution, now some of the methods were then summarized, therefore, we don't go to abandon some in the original belongs to the essence of things. Like sports history research of the older generation of scholars focus on research for decades, as the ideal, target, persistent pursuit of spirit is worth our study, is always valuable.

\section{REFERENCE}

[1] Liu L., 2014, Quantitative study and analysis for English integrated teaching based on Matlab. J. Chem. Pharm. Res., 6(5): 1937-1941.

[2] Jiang Han, 2014, Chinese mens basketball team development countermeasure research based on analytic hierarchy process. J. Chem. Pharm. Res., 6(5): 1929-1936.

[3] Li Feng, Jia Xiaoxuan, Du Geng, Ebadi Abdol Ghaffar, 2013, The analysis of factors affecting the development of tennis based on principal component analysis. Biotechnol. An Indian J., 8(6):738-743.

[4] Song WenZu, 2013, Study on the analysis and simulation of fosbury flop technique based on the sports biomechanics. Biotechnol. An Indian J., 8(10): 1331-1336.

[5] Chen Chao, Lu Guang, Ebadi Abdol Ghaffar,2013, Mathematical model of nonlinear distortion and linear error correction for soccer robot vision system. Biotechnol. An Indian J., 8(6): 733-737.

[6] Liang Tiehuai , 2013, Based on the statistics of the long jump athletes three-dimensional force analysis of jumping. Information Technology Journal, 12(15): 3345-3348. DOI: 10.3923/itj.2013.3345.3348.

[7] Pu Sheng, 2013, Biomechanical analysis of the influencing factors on fitness running leg's stomp effect. Information Technology Journal, 12(19): 5085-5090. DOI: 10.3923/itj.2013.5085.5090.

[8] Xing Jinming, Jiang Yong, Yuan Wenxue, Liu Liqing, 2013, The application of grey comprehensive evaluation model in the sports industry research. International Journal of Applied Mathematics and Statistics, 48(18): 461-468.

[9] Tang Dingyu, Ma Gang, Guo Jun, 2013, Applications of Monte Carlo algorithm in research on the basketball hit rate of ideal hollow shooting based on Matlab Simulation. Information Technology Journal, 12(15): 3315-3319. DOI: 10.3923/itj.2013.3315.3319. 
AUTHOR's BIOGRAPHY

Zhang Bing (1973 -) male, Mongolian, liaoning chaoyang, master degree, associate professor, research interests: sports industry and sports engineering, sports.

Address: No. 146, Xingang 2 Road, Huanggang City, Hubei Province, P.R.China (Institute of Physical Education, Huanggang Normal University) 